\title{
Article \\ Algorithmic Modelling of Advanced Chlorination Procedures for Multimetal Recovery
}

\author{
Lukas Höber ${ }^{1, *}$, Roberto Lerche ${ }^{2}$ and Stefan Steinlechner ${ }^{1}$ (1) \\ 1 Christian Doppler Laboratory for Selective Recovery of Minor Metals Using Innovative Process Concepts, \\ Chair of Nonferrous Metallurgy, Montanuniversität Leoben, 8700 Leoben, Austria; \\ stefan.steinlechner@unileoben.ac.at \\ 2 Chair of Nonferrous Metallurgy, Montanuniversität Leoben, 8700 Leoben, Austria; \\ roberto.lerche@unileoben.ac.at \\ * Correspondence: lukas.hoeber@unileoben.ac.at; Tel.: +43-3842-5227
}

Citation: Höber, L.; Lerche, R.; Steinlechner, S. Algorithmic Modelling of Advanced Chlorination Procedures for Multimetal Recovery. Metals 2021, 11, 1595. https:// doi.org/10.3390/met11101595

Academic Editor: Felix A. Lopez

Received: 31 August 2021

Accepted: 4 October 2021

Published: 8 October 2021

Publisher's Note: MDPI stays neutral with regard to jurisdictional claims in published maps and institutional affiliations.

Copyright: (c) 2021 by the authors. Licensee MDPI, Basel, Switzerland. This article is an open access article distributed under the terms and conditions of the Creative Commons Attribution (CC BY) license (https:// creativecommons.org/licenses/by/ $4.0 /)$.

\begin{abstract}
In the course of developing an innovative process for $\mathrm{CO}_{2}$-optimised valuable metal recovery from precipitation residues accumulating in the zinc industry or nickel industry, the chlorination reactions were investigated. As the basis of small-scale pyrometallurgical experiments, the selected reaction systems were evaluated by means of thermodynamic calculations. With the help of the thermochemical computation software FactSage (Version 8.0), it is possible to simulate the potential valuable metal recovery from residual materials such as jarosite and goethite. In the course of the described investigations, an algorithmically supported simulation scheme was developed by means of Python 3 programming language. The algorithm determines the optimal process parameters for the chlorination of valuable metals, whereby up to 10,000 scenarios can be processed per iteration. This considers the mutual influences and secondary conditions that are neglected in individual calculations.
\end{abstract}

Keywords: jarosite; goethite; multimetal recovery; advanced chlorination

\section{Introduction}

For the large quantities of precipitation residues that are generated in the course of hydrometallurgical zinc and nickel production, a variety of processes to recover valuable elements have been developed and followed up to different scales [1]. With a global annual zinc production of 13 to 13.5 million tons in 2019, it is the third most produced nonferrous metal after aluminium and copper [2,3]. The majority of zinc is obtained via the hydrometallurgical route whereby significant amounts of iron precipitation residues such as jarosite, goethite, or hematite are generated [4]. In a similar way, the nickel industry also uses iron precipitation steps for solution cleaning [5]. The only process applied worldwide to treat these materials is the Jarofix process, which produces an inert material through the immobilization of the residual fractions that can be safely deposited [6-8].

In addition to the ecological disadvantages such as land consumption and potential hazards to groundwater $[9,10]$, the loss of significant amounts of valuable metals has to be mentioned. Iron precipitation can contain elements such as $\mathrm{Zn}, \mathrm{Pb}, \mathrm{Ni}, \mathrm{Cu}, \mathrm{In}, \mathrm{Ag}$, Ge, $\mathrm{Ga}$, and $\mathrm{Sb}$ in noteworthy extents [11-16]. To date, only a few smelters with operating processes for the recovery of contained valuable metals on an industrial level have been reported [12].

In a novel process concept, the simultaneous recovery of a number of valuable metals by selective chlorination via different chlorine carriers is being investigated. Hereby, the reactions take place without any addition of carbon as a reducing agent, resulting in a significant reduction in the greenhouse gas emissions. Due to the large variety of valuable metals contained in precipitation residues, different available chloride materials, and influences such as atmospheres and additives, a large number of different parameters can influence 
the extraction behaviour of the respective metal. In order to determine the optimum reaction mixtures, process parameters, and potential other influences, the thermochemical software package FactSage (Version 8.0, GTT-Technologies, Aachen, Germany), [17], with its integrated Equilib module, can be used. In the course of the described research, algorithms were developed using the Python 3 [18] programming language, which allow for the investigation and automated evaluation of several thousand different reaction scenarios in one computational run. This facilitates the evaluation of the influence of a large number of different, mutually influencing parameters on the extraction rates of any valuable metal to be investigated prior to experimental evaluations. The results of the simulation were in turn evaluated via a programmed algorithm. The process sequence presented here is decidedly designed for the simulation-based investigation of chlorination reactions with subsequent evaporation of the resulting chlorides. Moreover, it can be adapted to all other evaporation reactions by minor modifications. Furthermore, it is, in principle, possible to extend the process scheme of the algorithm-supported evaluation of thermodynamic calculations to any other reaction systems calculated in the FactSage Equilib module. The purpose of this publication is to give both an overview on the generated data when simulating chlorination reactions in the absence of carbon as well as the potential of the developed simulation procedure in general.

\section{Materials and Methods}

Methodically, the modelling approach can be divided into three logical dimensions that offer different degrees of freedom, as shown in Figure 1.

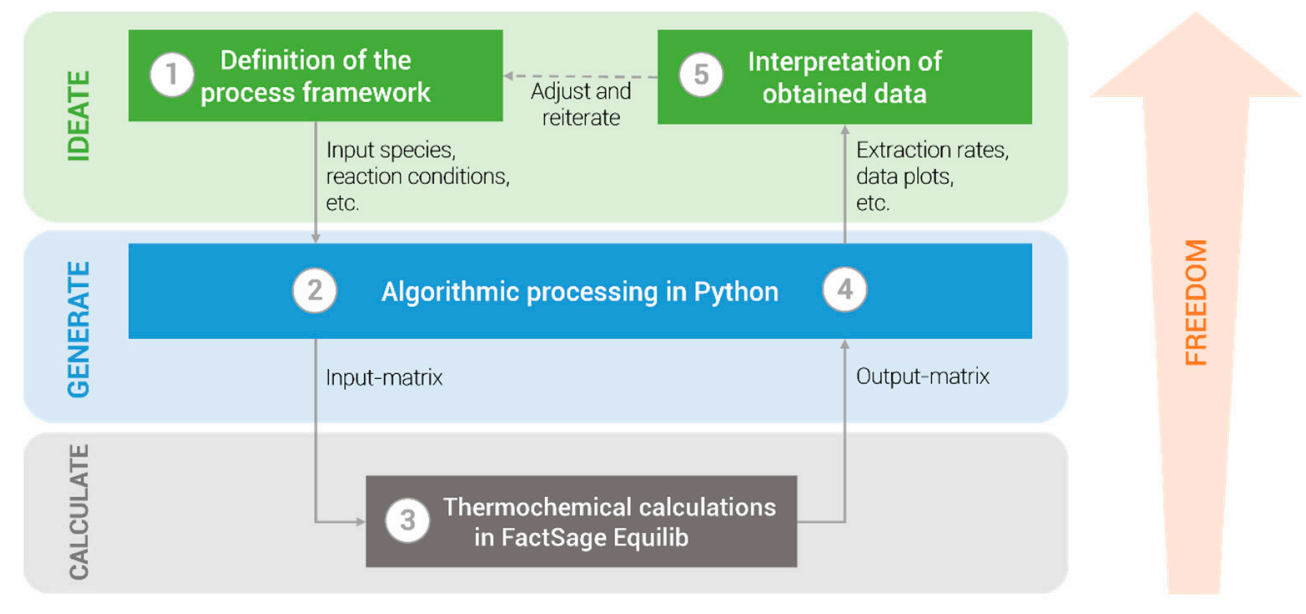

Figure 1. Schematic visualization of the modelling approach.

\subsection{Definition of the Process Framework}

In the first ideation process, major outlines of the to be assessed reaction system must be defined. This includes the metals desired to be extracted, the solid chlorination agents (SCA), atmospheric compounds, and supplementary secondary species, which are present in the reaction mixture. All species included in FactSage's comprehensive database are available for simulation and are defined by their respective chemical formula. There is no combinatory limitation in the selection of reactants. These can be derived from the literature, practical trials, or be of an intrinsically innovative nature. Generally, reactions that coincide with Equation (1) are pursued.

Compound of valuable metal (s) + Chlorine carrier (s/g) $\rightarrow$ Metal chloride (g)

\subsection{Primary Algorithmic Processing in Python}

Once the framework of the reactants is defined, reaction conditions are to be appointed directly in the primary Python algorithm. Apart from physical conditions such as temper- 
ature and pressure, information about the reactants' input quantities and stoichiometry must be set. There are several functions available including the evaluation of either individual metals or mixtures thereof, selection of their present form (oxidic, sulphatic, etc.), linear or logarithmic quantity ranges, and various stoichiometric models with regard to chlorine addition. The algorithm then processes all given details through the generation of a holistic input-matrix for the FactSage Equilib module, making use of the Python libraries NumPy [19], Pandas [20], and chemlib [21]. While iterating through all given values of each parameter, one line is filled with a unique set of information. As a consequence, a two-dimensional structure is generated, where each row represents one single reaction scenario, covering all possible configurations of input data as a whole.

\subsection{Thermochemical Calculations in FactSage Equilib}

The thereby obtained matrix is the foundation for thermochemical calculations conducted in the FactSage Equilib module. Due to the lack of automatization possibilities, all input species must be defined in the reactants' table window. However, by importing the generated input-matrix into FactSage, all of the required data are registered. Although there is no technical limitation to the matrix size from a generation perspective, FactSage reveals multiple restrictions. Consequently, a maximum of 9999 scenarios for up to 48 reactants can be assessed in one calculation run. The software determines the product species as well as their quantities and apparent phase for each individual scenario based on the fundamental laws of thermodynamics. These results can be exported as an output-matrix, which contains the data of all reaction outcomes.

\subsection{Secondary Algorithmic Processing in Python}

The product data contained in each row of the output-matrix is directly associated with a precise reaction scenario given in the respective row of the input-matrix. This allows for the evaluation of the extraction success using another Python algorithm. By calculating the extraction rates according to Equation (2), it is then possible to determine the success of evaporation of the desired metal.

$$
E_{\text {met }}=N_{\text {met,out, (g) }} /\left(N_{\text {metComp,in,(s) }} n_{\text {met,metComp }}\right)
$$

where $E_{\text {met }}[-]$ is the extraction rate; $N_{\text {met,out,(g) }}[\mathrm{mol}]$ is the number of gaseous moles of the metal in the reaction's product as calculated by FactSage Equilib; $N_{\text {metComp,in,(s) }}$ [mol] is the number of reacting moles of the input metal compound; and $n_{\text {met,MetComp }}[-]$ is the number of moles of metal per mole metallic compound. Through the development of a flexible algorithm, the rate's dependencies of the variation of all available parameters can be visualized by using the libraries Matplotlib [22] and seaborn [23].

\subsection{Interpretation of the Obtained Data}

Finally, all obtained data are interpreted in a secondary ideation process. Conclusions about (un)favourable scenarios as well as (dis)advantageous reaction conditions for an efficient extraction of desired metals can be drawn. As new insights are gained in every simulation run, a gradually deeper understanding of the assessed processes can be acquired and applied in subsequent runs. Through alterations of the original reaction framework, learnings can be easily implemented in novel simulations. Therefore, the entire approach can be considered as an iterative cycle.

The calculations were carried out using FactSage thermochemical software and databases v8.0. The integrated module Equilib simulates the reaction of freely selectable compounds according to the thermodynamic laws and data from its database. In general, the module can be used to calculate the stable products, which are generated during the reaction of a number of reactants under specific conditions such as the adjustable pressure or temperature. In the basic application, only one variable is provided for the iteration of a specific quantity range. Thus, no individual ranges for specific reactants can be realized, requiring the conduction of one calculation run for each species desired to be indepen- 
dently iterated while the others remain constant. However, by means of the "Reaction Table" function, it is possible to read in predefined reaction systems. These can be created manually or, as in case of this research project, with the help of an algorithm.

In the course of the thermodynamic calculations in FactSage, the investigated chemical compounds were considered as shown in the Results section. Since the thermodynamic data for compounds such as jarosite were not available in the databases, mixtures of the metal compounds formed during their thermal treatment were considered as an approximation. In the simulations performed to evaluate the extraction behaviour of whole mixtures, the chemical composition was chosen as given in Table 1 . The concentrations were in the range representative for a real industrial jarosite residue, which is why this mixture is referred to as "mock jarosite". The elements were considered in the form of their stable oxides.

Table 1. Chemical composition of the investigated mixture.

\begin{tabular}{cc}
\hline Element & Concentration (wt \%) \\
\hline $\mathrm{In}$ & 0.024 \\
$\mathrm{Ag}$ & 0.024 \\
$\mathrm{Zn}$ & 4.1 \\
$\mathrm{~Pb}$ & 4.4 \\
$\mathrm{Fe}$ & 29 \\
\hline
\end{tabular}

\section{Results}

The results shown are those from a simulation of a realistic metal oxide mixture of thermally treated jarosite, as given in Section 2. These compounds react with different chlorides under numerous varying parameters. The primary purpose of this section is to illustrate the wide range of information that can be obtained from the simulation scheme presented. As described earlier, the simulation procedure is very easily applicable to any extraction procedure using thermal evaporation.

Due to the large number of parameters studied in the simulation, the results cannot be shown in conventional ways. This circumstance can be counteracted by considering a selected parameter over the averaged values of all other parameters. Therefore, the extraction rates of the five considered elements from their oxidic compounds during the course of the reaction with different chlorination agents were calculated as depicted in Figure 2. The chlorination reactions were investigated considering both the pure metal oxides as well as the mixtures as given in the materials and methods section. All other influences such as atmospheres, additives, etc. are considered via the mean extraction rates over their varying values. The main difference between individual assessments of pure metals and mixtures is the existence of their competing character for chlorination in the latter case. Generally, the desired metals already evaporated at lower temperatures than iron when being present in a mixture. This behaviour suggests that observed metals have a higher affinity to chlorine.

In addition to the type and quantity of chlorination agents, the atmosphere can have a significant influence on the chlorination procedure. Figure 3 shows the calculated extraction rates of specific metals from the investigated mixture in chlorination procedures in dependence of the temperature for four different atmospheres. In terms of chlorinating valuable metals from residual materials such as jarosite, one of the most important aspects is the selective separation from the dominant remaining iron matrix. As can be seen in Figure 3, the extraction of iron only occurs at significantly higher temperatures for all atmospheres. This allows for the separation of the valuable metal chlorides without significant iron losses and iron impurities, respectively, in the obtained valuable metalchloride products. 


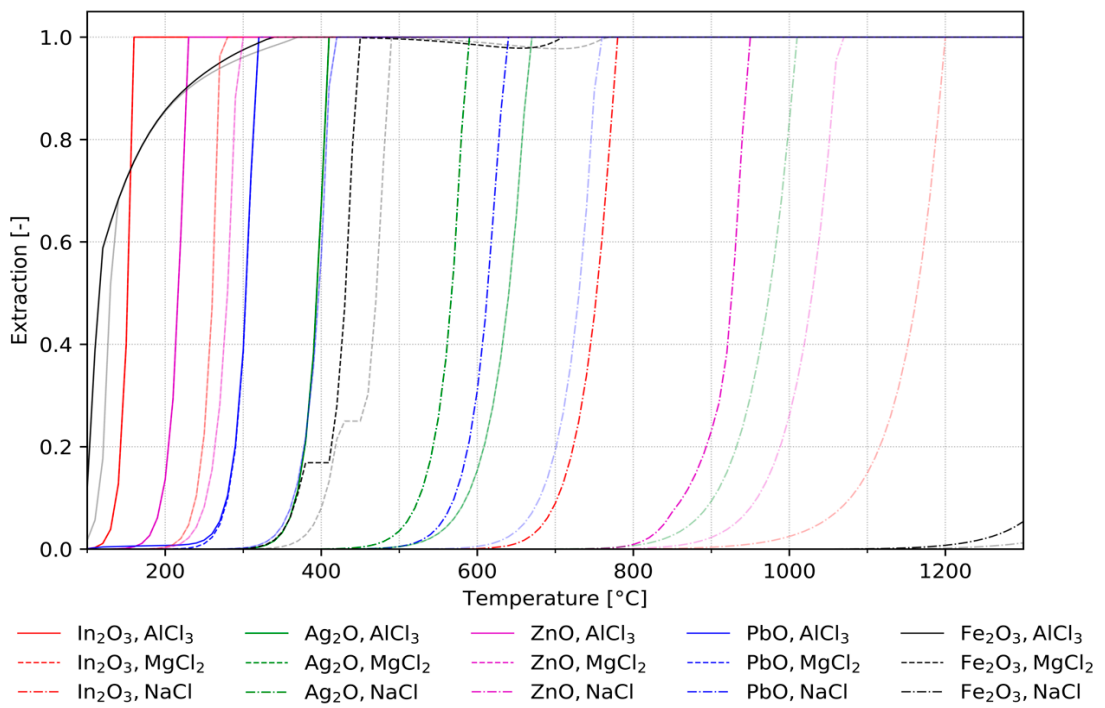

Figure 2. Comparison of extraction rates of individually assessed metals (transparent lines) and from mixtures (bold lines) as a function of temperature.

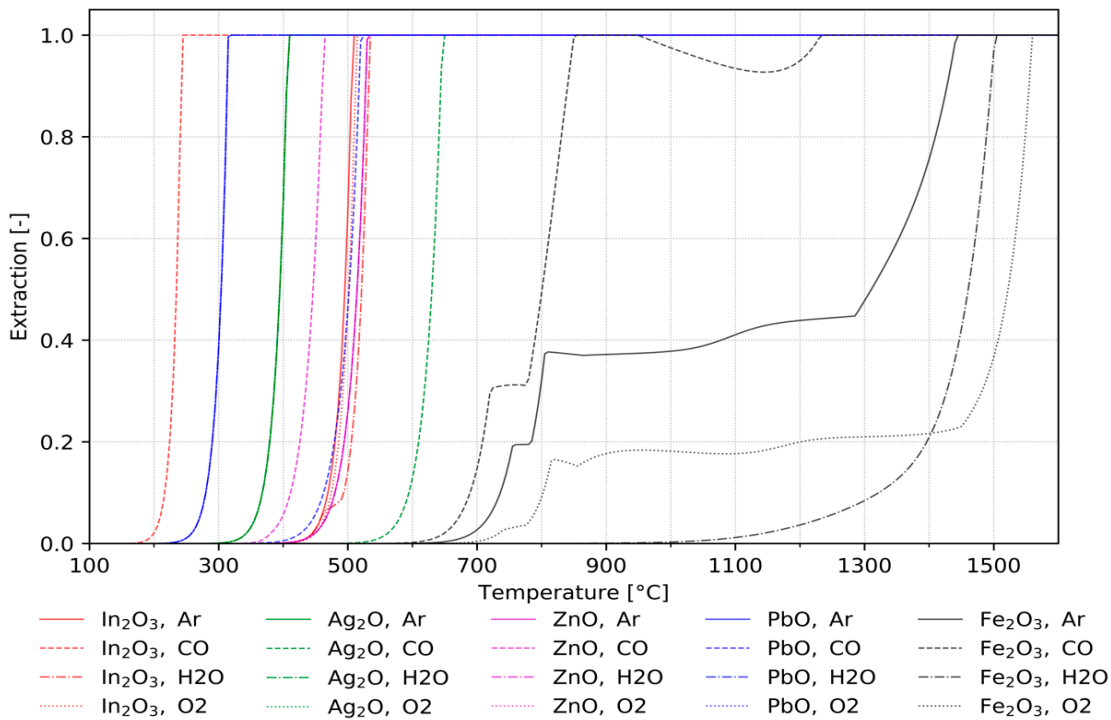

Figure 3. Influence of temperature and atmosphere on the extraction rates from mock jarosite.

The data generated during the course of the simulation can also be used for more precise interpretations of the chlorination behaviour of specific elements. As already mentioned, the chlorination of iron should be as low as possible. In general, it can be stated that the chlorination of iron is poorer compared to the valuable metals, since the iron chloride is less stable. Furthermore, in the course of this research, other effects that reduced the extraction of iron could also be demonstrated. Figure 4 shows the formation of various solid and gaseous compounds during the chlorination of mock jarosite using $\mathrm{CaCl}_{2}$ with a focus on iron. In the presence of calcium, iron oxide was found to form the compound $\mathrm{Ca}_{2} \mathrm{Fe}_{2} \mathrm{O}_{5}$, which is stable at temperatures up to $1000^{\circ} \mathrm{C}$, hindering the chlorination and evaporation of iron oxide. 


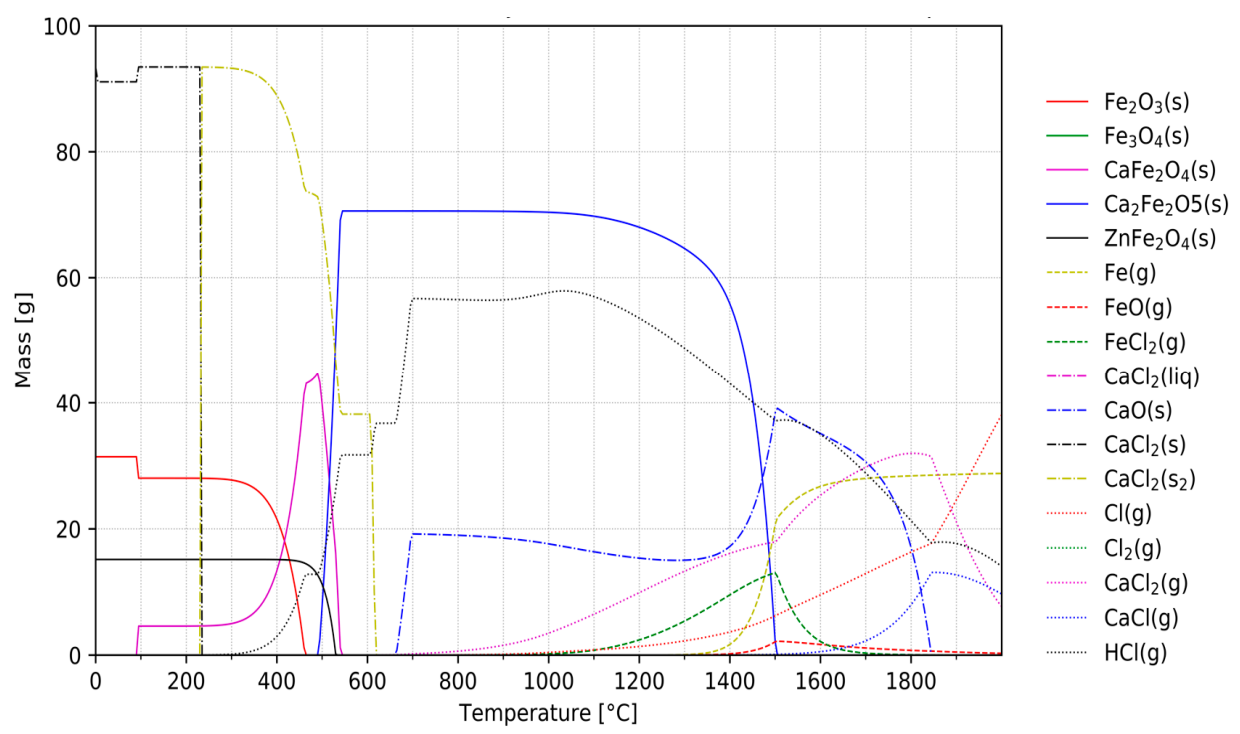

Figure 4. Formation of various solid (solid lines) and gaseous (dashed lines) iron compounds as well as solid (dash dotted) and gaseous (dotted) compounds of $\mathrm{CaCl}_{2}$ during the chlorination of mock jarosite as a function of temperature.

\section{Introducing the Valex-Factor for Reduced Complexity}

Due to the large amount of data generated when evaluating the extraction of multiple valuable metals, the representation of various influences becomes complex. For this reason, a new factor was introduced, which summarizes the extraction rates of the value metals into one key figure. The valex-factor (valuable-extraction) is calculated as given in Equation (3). $E_{\text {met }}$ is the metal's extraction rate and $P_{\text {met }}$ is its current market price. The factor can be interpreted as the ratio of financial output achieved by the extraction of value embodied by the contained valuable metals in the mock jarosite material, ranging from zero to one.

$$
\text { Valex }=\frac{\sum_{\text {met }} E_{\text {met }} \cdot P_{\text {met }}}{\sum_{\text {met }} P_{\text {met }}}
$$

The valex-factor is used to gather useful information about the practicability of certain reaction systems as it shows the overarching financial potential of the chlorination process. In addition to the valex-factor, the iron extraction as well as the difference of the two mentioned factors were considered. A key value that is used for the evaluation of the separation is the difference in the valex-factor and five-fold of the iron extraction.

The following visualizations in Figures 5-8 show the wide variety of informative data that are generated during the course of the simulation process. Comprehensive information about the chlorination behaviour was obtained when looking into the influence of the amount of added SCAs and temperature. Figure 5 shows the valex-factor as well as the iron extraction. The valex-factor increased significantly with rising temperature even when the amount of chlorine present was low. At high temperatures $\left(1200{ }^{\circ} \mathrm{C}\right)$, unfavourable iron extraction also reached high values. Raising the amounts of added chlorine produced the same effect, though less pronounced.

Figure 6 gives an overview of the influence of the chlorination agent, secondary compounds, and different atmospheres. It is evident that the choice of the chlorination agent $\left(\mathrm{AlCl}_{3}, \mathrm{FeCl}_{3}\right.$, or $\left.\mathrm{MgCl}_{2}\right)$ was not as much of a strong influence on the chlorination behaviour as certain additives and atmospheres. As shown in Figure $6 \mathrm{~g}$, an optimal temperature range for a selective extraction behaviour exists. While the extraction of valuables was hindered at low temperatures, it increased significantly with increasing temperature levels. However, the iron extraction also reached significant values when exceeding $800{ }^{\circ} \mathrm{C}$, increasingly compromising the valuable extraction, as can be seen by the declining bars. At this point, it must be noted that the extraction of iron only took 
place at rates up to $25 \%$ (influence $\mathrm{CaF}_{2}$ at $1200{ }^{\circ} \mathrm{C}$ ). In addition to the predominant trends, the diagrams provide information on the effect of individual additives and atmospheres. The addition of $\mathrm{SiO}_{2}, \mathrm{CaF}_{2}$, and $\mathrm{FeS}_{2}$ increased the extraction of valuable elements to a similar extent as the other additives, which had a particular effect on the unwanted extraction of iron. This caused a decrease in values in the Figure $6 \mathrm{~h}$ diagram (valex-5-fold of iron-extraction) for temperatures above $800{ }^{\circ} \mathrm{C}$. For $\mathrm{K}_{2} \mathrm{SO}_{4}$ and $\mathrm{Ca}(\mathrm{OH})_{2}$, as can be seen, the best values were obtained at higher temperatures.

As depicted in the Figure $6 \mathrm{i}$, a reducing atmosphere $(\mathrm{CO})$ had a negative influence on the separation. Oxygen and water showed a positive tendency, whereas that of oxygen decreased again at $1200{ }^{\circ} \mathrm{C}$. The inert argon atmosphere showed a positive influence at low temperatures. For the sake of completeness, the influence of $\mathrm{SO}_{2}$, which is formed during the thermal decomposition of jarosite, was also investigated, and behaved similarly to that of argon.

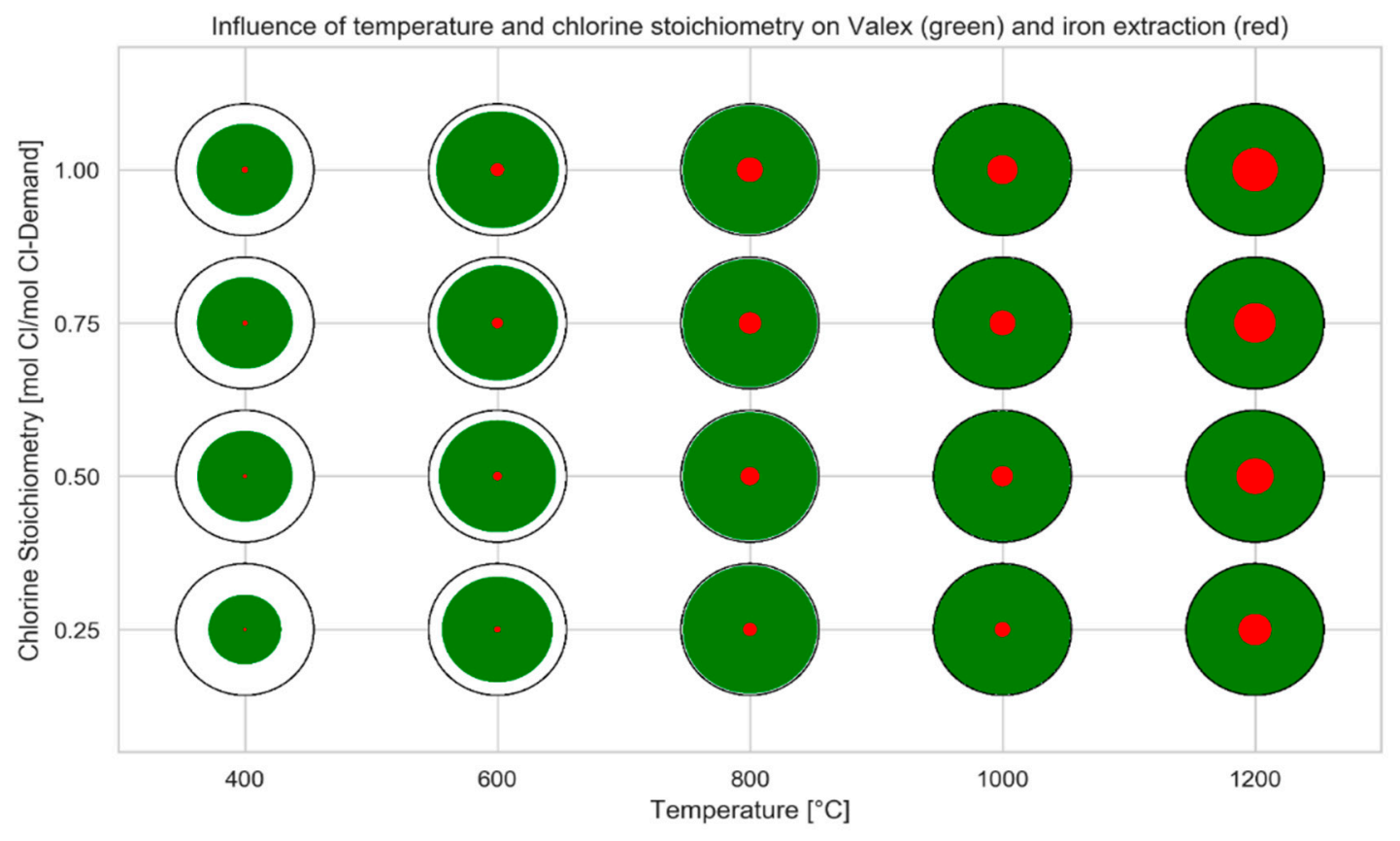

Figure 5. Influence of temperature and chlorine stoichiometry on mean valex (green) and iron extraction (red) including all previously stated parameters; the black circle represents a value of 1.00 .

Furthermore, it is possible to take a closer look into the extraction rates at certain temperatures. The influences of atmospheres and secondary compounds on the valexfactor at $600{ }^{\circ} \mathrm{C}$, where the overall chlorination capacity was expected to be lower, are given in Figure 7. Here, the deviation of the extraction from the mean value over all simulation steps was taken into account. It was shown that the extraction was significantly hindered by a reducing $\mathrm{CO}$-atmosphere. On the other hand, the inert argon atmosphere as well as oxygen and $\mathrm{SO}_{2}$ showed a more positive effect. For each considered atmosphere, the influence of specific secondary compounds is given. The presence of $\mathrm{SiO}_{2}$ had a positive effect on the valex-factor while, for example, $\mathrm{K}_{2} \mathrm{SO}_{4}$ hindered extraction.

Another aspect that was closely investigated was the present form of the used chlorination agents. In general, metal chlorides are found to be hydrophilic, which means that they easily react with water and form hydrates. Figure 8 shows the difference between the valex value and the 5 -fold iron-extraction for the chlorination with anhydrous or hydrated chlorides in dependence of numerous secondary compounds and different atmospheres. The values showed the mean values over all other parameters. It is evident that the chlorination worked significantly better when the chlorides were present in the hydrate form. The form of chloride was, as expected, of no influence when the reaction took place in a 
water-steam carrying atmosphere. On the other hand, the influence was pronounced in a reductive CO-atmosphere as well as in the presence of $\mathrm{CaF}_{2}, \mathrm{FeS}_{2}$, or $\mathrm{SiO}_{2}$ as additives.

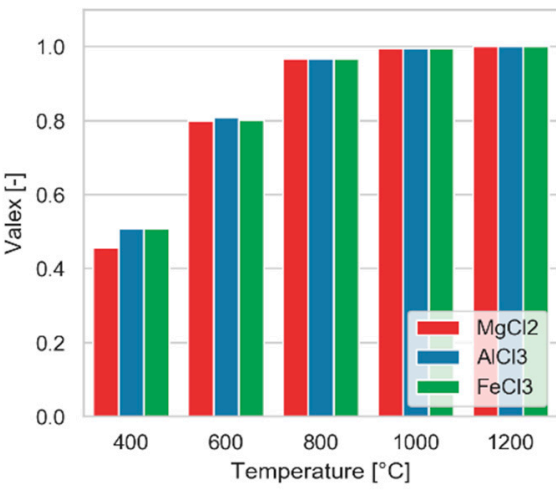

(a)

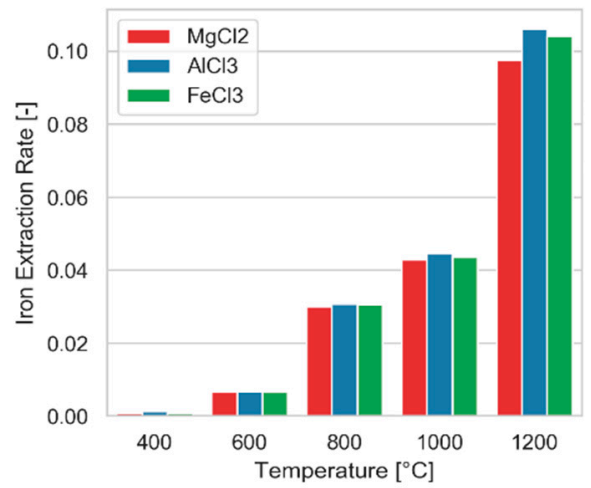

(d)

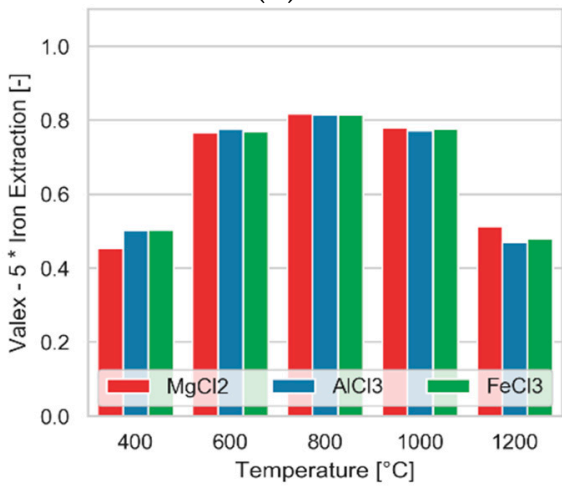

(g)

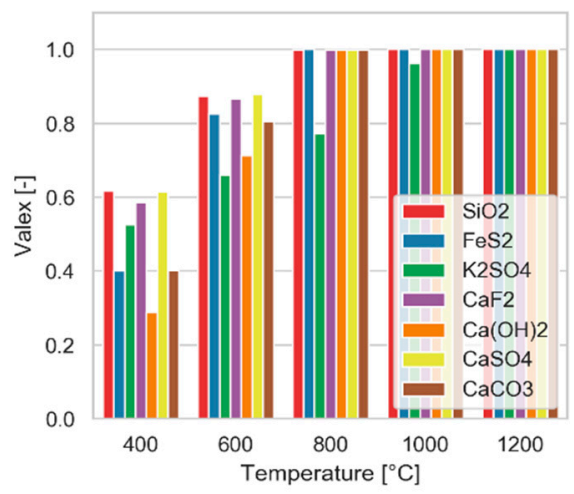

(b)

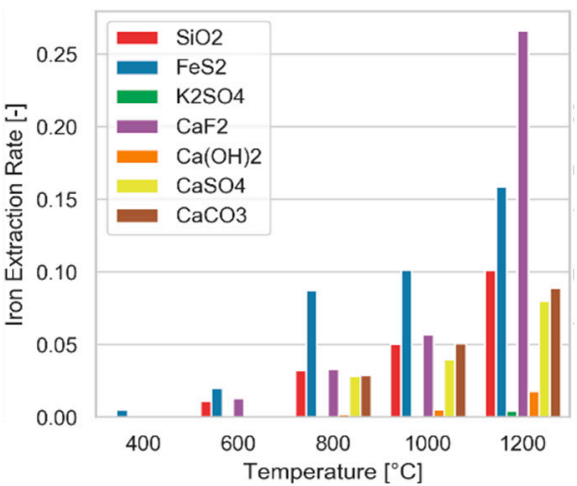

(e)

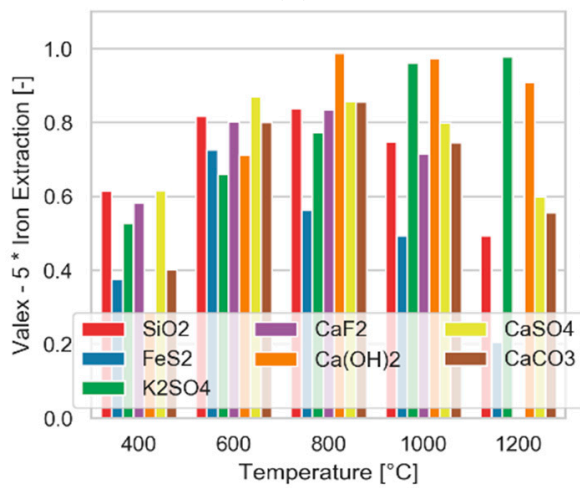

(h)

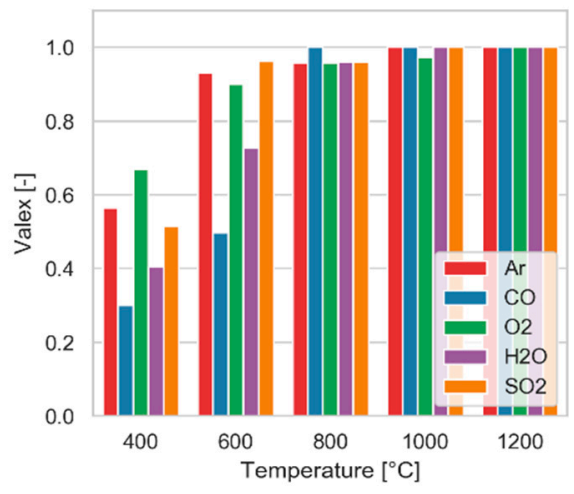

(c)

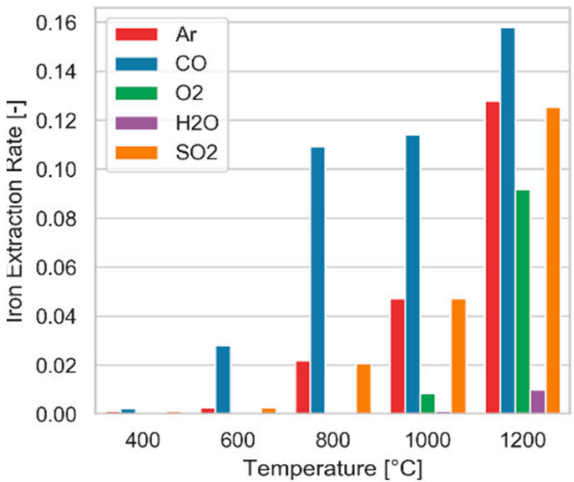

(f)

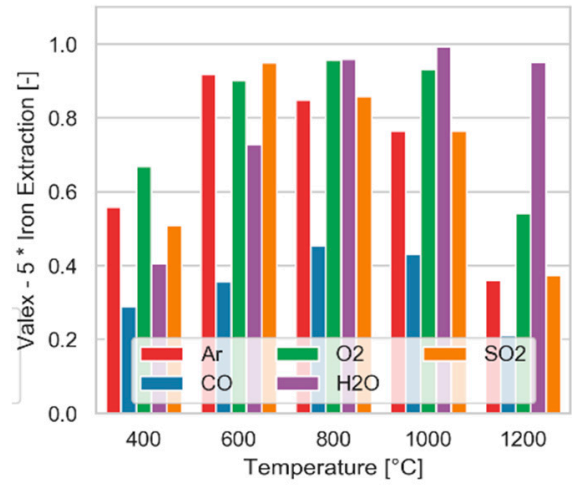

(i)

Figure 6. Influence of various SCAs $(\mathbf{a}, \mathbf{d}, \mathbf{g})$, secondary compounds $(\mathbf{b}, \mathbf{e}, \mathbf{h})$, and atmospheres $(\mathbf{c}, \mathbf{f}, \mathbf{i})$ on the extraction rates of valex $(\mathbf{a}-\mathbf{c})$ and iron $(\mathbf{d}-\mathbf{f})$ and the difference between both $(\mathbf{g}-\mathbf{i})$, where iron extraction was weighted 5 -fold, the pressure of $1 \mathrm{~atm}$, and chlorine stoichiometry of 1 . 


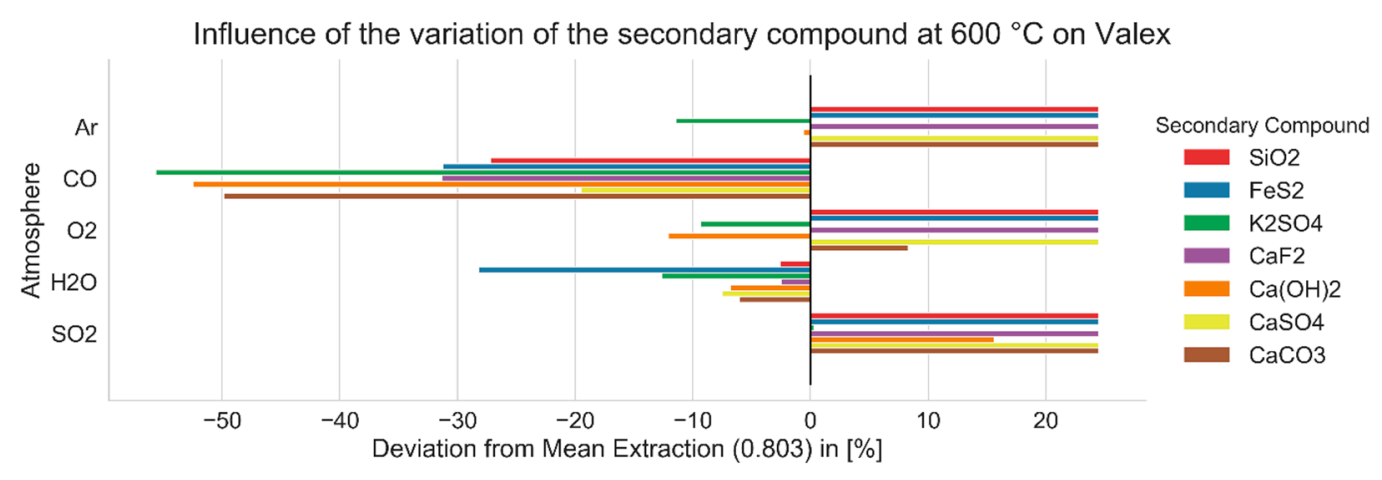

Figure 7. Influence of the variation of atmosphere and secondary compounds on valex rates at $600{ }^{\circ} \mathrm{C}, 1 \mathrm{~atm}$, and chlorine stoichiometry of 1 .

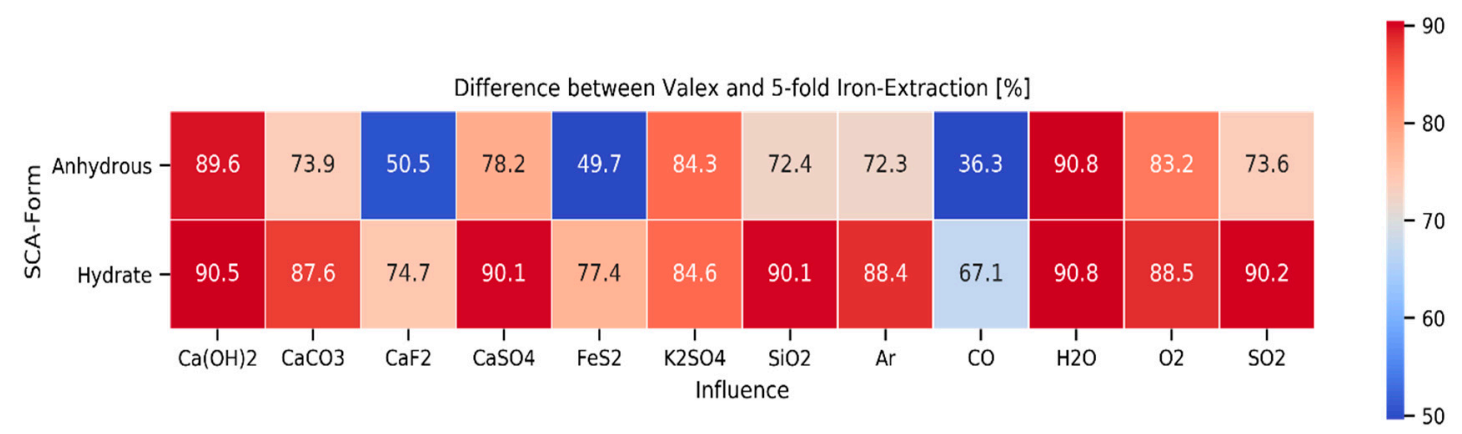

Figure 8. Difference between valex and 5-fold iron extraction for various atmospheres and secondary compounds in combination with anhydrous or hydrated SCAs, mean values for temperatures, pressure of 1 atm, and stoichiometry of 1 .

\section{Discussion}

The results that are given in this publication show an excerpt of the data that can be obtained in multivariate analyses using a combinatory scheme of FactSage computational software and Python algorithms. By simultaneously considering several dozens of mutually influencing parameters, it is possible to find a setup that provides the best possible extraction of the contained valuable metals from a mock jarosite material while leaving behind the iron fraction. Different chlorination agents were investigated, whereby it was found that bivalent and trivalent chlorides showed the best chlorination behaviour. It could be seen that the chlorination agents $\mathrm{AlCl}_{3}, \mathrm{FeCl}_{3}$, and $\mathrm{MgCl}_{2}$ provided similarly good values with respect to effective chlorination whereas the effectivity of $\mathrm{CaCl}_{2}$ was lower. On the other hand, a very strong influence was given by the amount of chlorides added. However, the addition was limited as it was associated with a lowering of the process performance, which was caused by increased chlorination and evaporation of iron. The same behaviour was observed at too high process temperatures, where values of $800-1000{ }^{\circ} \mathrm{C}$ were found to provide the best results.

With regard to other influencing factors, several additives were evaluated in addition to various atmospheres. In general, it can be stated that chlorination proceeded preferentially in oxidizing and inert atmospheres, while a reducing atmosphere caused a comparably negative effect. The interpretation of the effect of certain additives is difficult because first, the influence is rather small and second, they are difficult to control in real processes. The form in which the chlorides are present also has a major influence. Hydrated chlorides as well as the presence of water in general provoke a strong increase in an overall effectivity of the process.

Despite the great variety of obtainable insights, their theoretical nature must be pointed out. Since the scope of present simulation processes is limited to theoretical calculations, they cannot be directly translated to real reactions. Some potentially tremendous effects on chlorination reactions cannot be implemented into the proposed simulation scheme. Due to the inhomogeneity of real mixtures, which is further enhanced via incomplete mixing 
and segregation, deviations in real experiments can be expected. This is due to the fact that no complete contact of each present compound can be achieved under real process conditions [24]. The inhomogeneity can furthermore be increased by the melting of solid phases, which reduces the particle porosity. Therefore, the penetration of gaseous chlorine compounds is inhibited [25]. Moreover, the temperature is not always homogeneously distributed throughout the mixture. Various reaction routes are possible simultaneously on different locations of the material. All mentioned influences affect reaction kinetics, which are neglected in basic thermochemical calculations and can only be assessed by experimental investigation.

\section{Conclusions}

Algorithmic modelling of metallurgical reactions is becoming widely used as it offers the possibility of evaluating a huge variety of influencing parameters to find the optimal process conditions. Thermochemical simulation packages like the Equilib module in the FactSage software offer a way to simulate chemical reactions in a user-friendly way. However, due to the small number of variable parameters in the conventional mode of use, multivariant evaluation of chemical reactions is practically impossible. By using algorithmsupported methods for generating importable sets of start data and their subsequent merging with the generated results, it is possible to investigate a large number of different influences. In this way, up to about 10,000 scenarios can be assessed with only one simulation process. By evaluating with programmed algorithms, it is possible to find the strongest influencing parameters as well as the mutual influences of the different parameters and enable in depth interpretation of the reaction events.

In the present publication, this process approach was demonstrated during the course of the investigation of carbon-free chlorination processes for the extraction of valuable metals from precipitation residues in the form of decomposed jarosite or goethite. The present process concept makes it possible to find valuable information for the best possible treatment of a residue that has not been examined in detail beforehand, if a chemical analysis of the treated material is available. Because the algorithmic evaluation code can be freely adapted as required, it is possible to incorporate data external to the simulation such as the current market prices of the valuable metals.

Author Contributions: Conceptualization, L.H. and R.L.; Methodology, L.H. and R.L.; Software, R.L.; Validation, L.H., R.L. and S.S.; Investigation, R.L. and L.H.; Writing-original draft preparation, L.H. and R.L.; Writing-review and editing, S.S. All authors have read and agreed to the published version of the manuscript.

Funding: This research was funded by Austrian Federal Ministry for Digital and Economic Affairs and the National Foundation for Research, Technology and Development and the Christian Doppler Research Association.

Data Availability Statement: The data presented in this article are available on request from the corresponding author.

Conflicts of Interest: The authors declare no conflict of interest. The funders had no role in the design of the study; in the collection, analyses, or interpretation of data; in the writing of the manuscript, or in the decision to publish the results.

\section{References}

1. Hoeber, L.; Steinlechner, S. A comprehensive review of processing strategies for iron precipitation residues from zinc hydrometallurgy. Clean. Eng. Technol. 2021, 4, 100214. [CrossRef]

2. International Lead and Zinc Study Group. ILZSG SPRING 2019 MEETINGS/FORECASTS. Available online: http://www. mineralinfo.fr/sites/default/files/upload/ilzsg_may_2019_press.pdf (accessed on 8 April 2020).

3. USGS. ZINC: U.S. Geological Survey, Mineral Commodity Summaries. January 2020. Available online: https://pubs.usgs.gov/ periodicals/mcs2020/mcs2020-zinc.pdf (accessed on 8 April 2020).

4. Sinclair, R.J. The Extractive Metallurgy of Zinc; Australasian Institute of Mining and Metallurgy: Carlton South, Australia, 2005; ISBN 9781613442166. 
5. Crundwell, F.; Moats, M.; Ramachandran, V.; Robinson, T.; Davenport, W.G. Extractive Metallurgy of Nickel, Cobalt and Platinum Group Metals, 1st ed.; Elsevier Professional s.l.: Amsterdam, The Netherlands, 2011; ISBN 0080968090.

6. Sinha, A.K.; Havanagi, V.G.; Shahu, J.T. Stabilised jarofix waste material for road construction. Int. J. Pavement Eng. 2019, 170, 882-893. [CrossRef]

7. Chen, T.; Dutrizac, J. Jarofix: Addressing iron disposal in the zinc industry. JOM 2001, 53, 32-35. [CrossRef]

8. Chen, T.T.; Dutrizac, J.E. A Mineralogical Study of Jarofix Products for the Stabilization of Jarosite Residues for Disposal. In Lead-Zinc 2000: Proceedings of the Lead-Zinc 2000 Symposium Which Was Part of the TMS Fall Extraction E Process Metallurgy Meeting, Pittsburgh, PA, USA, 22-25 October 2000; Dutrizac, J.E., Ed.; TMS: Warrendale, PA, USA, 2000; pp. 917-934. ISBN 9781118805558.

9. Kerolli-Mustafa, M.; Ćurković, L.; Fajković, H.; Rončević, S. Ecological Risk Assessment of Jarosite Waste Disposal. Croat. Chem. Acta 2015, 88, 189-196. [CrossRef]

10. Kerolli-Mustafa, M.; Fajković, H.; Rončević, S.; Ćurković, L. Assessment of metal risks from different depths of jarosite tailing waste of Trepça Zinc Industry, Kosovo based on BCR procedure. J. Geochem. Explor. 2015, 148, 161-168. [CrossRef]

11. Palden, T.; Regadío, M.; Onghena, B.; Binnemans, K. Selective Metal Recovery from Jarosite Residue by Leaching with AcidEquilibrated Ionic Liquids and Precipitation-Stripping. ACS Sustain. Chem. Eng. 2019, 7, 4239-4246. [CrossRef]

12. Creedy, S.; Glinin, A.; Matusewicz, R.; Hughes, S.; Reuter, M. Ausmelt Technology for Treating Zinc Residues. World Metall.ERZMETALL 2013, 66, 230.

13. Calla-Choque, D.; Nava-Alonso, F.; Fuentes-Aceituno, J.C. Acid decomposition and thiourea leaching of silver from hazardous jarosite residues: Effect of some cations on the stability of the thiourea system. J. Hazard. Mater. 2016, 317, 440-448. [CrossRef] [PubMed]

14. UNEP. Metal Recycling: Opportunities, Limits, Infrastructure: This Is Report $2 b$ of the Global Metal Flows Working Group of the International Resource Panel of UNEP; United Nations Environment Programme: Nairobi, Kenya, 2013; ISBN 978-92-807-3267-2.

15. Wegscheider, S.; Steinlechner, S.; Leuchtenmüller, M. Innovative Concept for the Recovery of Silver and Indium by a Combined Treatment of Jarosite and Electric Arc Furnace Dust. JOM 2017, 69, 388-394. [CrossRef]

16. Malenga, E.N.; Mulaba-Bafubiandi, A.F.; Nheta, W. Alkaline leaching of nickel bearing ammonium jarosite precipitate using $\mathrm{KOH}, \mathrm{NaOH}$ and $\mathrm{NH} 4 \mathrm{OH}$ in the presence of EDTA and Na2S. Hydrometallurgy 2015, 155, 69-78. [CrossRef]

17. Bale, C.W.; Bélisle, E.; Chartrand, P.; Decterov, S.A.; Eriksson, G.; Gheribi, A.E.; Hack, K.; Jung, I.-H.; Kang, Y.-B.; Melançon, J.; et al. FactSage thermochemical software and databases, 2010-2016. Calphad 2016, 54, 35-53. [CrossRef]

18. Python Programming Language. Available online: https://www.python.org/ (accessed on 24 August 2021).

19. Harris, C.R.; Millman, K.J.; van der Walt, S.J.; Gommers, R.; Virtanen, P.; Cournapeau, D.; Wieser, E.; Taylor, J.; Berg, S.; Smith, N.J.; et al. Array programming with NumPy. Nature 2020, 585, 357-362. [CrossRef]

20. Reback, J.; jbrockmendel; McKinney, W.; Van den Bossche, J.; Augspurger, T.; Cloud, P.; Hawkins, S.; gfyoung; Sinhrks; Roeschke, M.; et al. Pandas-dev/Pandas: Pandas 1.3.2; Zenodo: Genève, Switzerland, 2021.

21. Ambethkar, H. Chemlib. Available online: https://github.com/harirakul/chemlib (accessed on 24 August 2021).

22. Hunter, J.D. Matplotlib: A 2D Graphics Environment. Comput. Sci. Eng. 2007, 9, 90-95. [CrossRef]

23. Waskom, M. Seaborn: Statistical data visualization. JOSS 2021, 6, 3021. [CrossRef]

24. Fraissler, G.; Jöller, M.; Mattenberger, H.; Brunner, T.; Obernberger, I. Thermodynamic equilibrium calculations concerning the removal of heavy metals from sewage sludge ash by chlorination. Chem. Eng. Process. Process Intensif. 2009, 48, 152-164. [CrossRef]

25. Lei, C.; Chen, T.; Yan, B.; Xiao, X.-M. Reaction characteristics and kinetics of gallium in chlorination roasting of copper tailings using calcium chloride. Rare Met. 2015. [CrossRef] 